\title{
SINTESIS GLISEROL STEARAT DARI ASAM STEARAT DENGAN GLISEROL HASIL SAMPING PEMBUATAN BIODISEL DARI MINYAK JELANTAH
}

\section{(SYNTHESIS GLYCEROL STEARATE OF STEARIC ACID WITH GLYCEROL BY PRODUCT OF BIODISEL FROM USED COOKING OIL)}

\author{
Ika Rosdiani dan Sri Atun \\ Fakultas Matematika dan Ilmu Pengetahuan Alam Universitas Negeri Yogyakarta \\ Jl. colombo No. 1 Yogyakarta \\ e-mail: sriatun@uny.ac.id
}

\begin{abstract}
Abstrak
Penelitian ini bertujuan untuk mensintesis gliserol stearat dari asam stearat dengan gliserol hasil samping pembuatan biodisel dari minyak jelantah, serta mengidentifikasi senyawa hasil sintesis dengan menggunakan spektroskopi IR dan GC-MS. Metode penelitian yang dilakukan adalah mereaksikan gliserol, asam stearat dan $\mathrm{HCl}$ pekat sebagai katalis, secara refluks pada temperatur $120-160{ }^{\circ} \mathrm{C}$ selama 8 jam. Hasil reaksi kemudian direkristalisasi dengan pelarut $n$-heksan. Senyawa hasil sintesis dikarakterisasi dengan menggunakan spektroskopi IR dan spektroskopi GC-MS. Dari penelitian ini diperoleh senyawa hasil sintesis berbentuk padatan berwarna putih kekuningan dan memiliki titik leleh $58-59{ }^{\circ} \mathrm{C}$ dengan rendemen $80,53 \%$. Spektrum IR senyawa hasil sintesis menunjukkan adanya gugus $\mathrm{C}=\mathrm{O}$ karbonil, $\mathrm{C}-\mathrm{O}$ ester, $-\mathrm{OH}$ dan $\mathrm{CH}$ alifatik. Analisis dengan GC-MS menunjukkan senyawa hasil sintesis memiliki kemiripan dengan gliserol 2-monostearat dengan indeks kemiripan (SI) sebesar 88\% dan kemurnian 98,94\%.
\end{abstract}

Kata kunci: asam stearat, gliserol, gliserol 2-monostearat, gliserol stearat

\section{Abstract}

The aim of this research is to synthesis glycerol stearate compound from stearic acid with glycerol by product of biodiesel from used cooking oil, and to determine of product using IR and GC-MS spectroscopy. Method of the research was esterification of glycerol and stearic acid with concentrated $\mathrm{HCl}$ as catalyst, by refluct at 120-160 OC for 8 hours. The result was recrystallized by $n$-hexan. The compound characterized by using IR spectroscopy and GC-MS spectroscopy. The compound has solid form, white to yellowish colour and has 5859 OC melting point value with rendement $80.53 \%$. IR spectrum showed the presence $C=O$ carbonil, $\mathrm{C}-\mathrm{O}$ ester, $-\mathrm{OH}$ and $\mathrm{C}-\mathrm{H}$ aliphatic group. The result of $\mathrm{GC}-\mathrm{MS}$ analysis showed the compound which have synthesized has similarities with glycerol 2-monostearate with similarity index (SI) of $88 \%$ with a purity of $98,94 \%$.

Keywords: glycerol, glycerol 2-monostearate, glycerol stearate, stearic acid

\section{PENDAHULUAN}

Minyak jelantah merupakan minyak yang dihasilkan dari sisa penggorengan atau minyak goreng yang dipakai berulang-ulang.
Minyak jelantah tersebut telah mengalami reaksi oksidasi dari asam lemak tidak jenuh membentuk gugus peroksida dan monomer siklik, sehingga menimbulkan dampak negatif 
bagi kesehatan(Ketaren,1996). Minyak jelantah dapat diolah menjadi biodisel, dengan produk samping gliserol melalui reaksi transesterifikasi sekitar $10-20 \%$ dari total volume produk (Darnoko, and Cheryan, 2000a,b). Gliserol merupakan cairan yang tidak berwarna, tidak berbau dan merupakan cairan kental yang memiliki rasa manis (Pagliaro dan Michele, 2008) dari gliserol tersebut bisa meningkat.

Gliserol dapat digunakan sebagai bahan dasar pembuatan berbagai produk turunan seperti gliserol triheptanoat, gliserol monostearat, lesithin, tri tetra butil gliserol, monogliserida oleat, gliserol triasetat, gliserol tribenzoat dan resin ester gliserol maleat (Widayat, 2012). Produk turunan gliserol tersebut banyak digunakan dalam industri kosmetik, makanan, kertas, tinta, plastik, maupun aditif bahan bakar biodiesel. Dalam penelitian ini telah dilakukan sintesis gliserol stearat melaluli reaksi esterifikasi asam stearat dengan gliserol hasil samping pembuatan biodisel dari minyak jelantah. Pembuatan gliserol stearat pernah dilakukan oleh Hilyati (2001) dengan mereaksikan antara gliserol dengan asam stearat pada suhu refluk $140-190{ }^{\circ} \mathrm{C}$ dengan waktu reaksi 8 jam dan katalis asam $\mathrm{HCl}$ diperoleh produk ester 94,58\%. Untuk mengetahui karakter gliserol stearat yang dihasilkan, maka dilakukan identifikasi penentuan titik leleh, identifikasi gugus fungsi dengan spektroskopi IR (Infra Red) dan spektroskopi GC-MS (Gas Chromatography-Mass. Spectrocophy).
Gliserol stearat ini merupakan surfaktan non ionik yang banyak digunakan dalam industri shampoo sebagai pearlizing agent, emulsifier dan lotion serta sebagai opacifier dalam industri ice cream dan makanan. Dengan demikian, pengembangan gliserol sebagai hasil samping dari biodiesel menjadi produk turunan gliserol dapat meningkatkan nilai jual gliserol tersebut.

\section{METODE PENELITIAN}

Alat yang digunakan dalam penelitian ini antara lain labu leher tiga (dilengkapi dengan pendingin balik, water bath, termometer dan magnetic stirer), beaker glass, erlemeyer, gelas ukur, buret, pipet tetes, pengaduk, spektrometer GC-MSQP2010S Shimadzu, spektrometer FTIR Prestige 21 Shimadzu, penyaring panas, corong, corong buchner, gelas arloji, kertas saring, lampu, alat penentu titik leleh dan pipa kapiler. Sedangkan bahan-bahan yang digunakan adalah gliserol hasil samping pembuatan biodisel dari minyak jelantah yang telah dimurnikan dengan kemurnian $98,5 \%$, asam stearat, $\mathrm{HCl}$ p.a sebagai katalis, n-hexan teknis, dan n-hexan p.a.

Langkah yang dilakukan adalah memasukkan 2,56 g gliserol ke dalam labu leher tiga dan ditambahkan asam stearat sebanyak 7,9 g yang telah dipanaskan terlebih dahulu di dalam gelas beaker serta asam klorida sebagai katalis. Campuran selanjutnya direfluks pada temperatur 
120-160 ${ }^{\circ} \mathrm{C}$ selama 8 jam. Hasil sintesis tersebut kemudian dimurnikan dengan rekristalisasi menggunakan pelarut n-heksan teknis 1:4. Campuran endapan hasil sintesis dengan pelarut dipanaskan perlahan hingga mencair, pemanasan ini dilakukan dengan pengadukan. Hasil rekristalisasi didinginkan dan didiamkan selama $\pm 30-60$ menit. Setelah terbentuk endapan lagi, disaring menggunakan penyaring buchner. Selama penyaringan, endapan dicuci sebanyak $2 x$ dengan pelarut. Hasil penyaringan ditempatkan pada gelas arloji dan dikeringkan dibawah lampu selama semalam. Kemudian hasil rekristalisasi diukur titik leleh dan dikarakterisasi menggunakan spektroskopi IR dan GC-MS.

\section{HASIL DAN PEMBAHASAN}

\section{Sintesis Derivat Gliserol dengan Asam Stearat}

Percobaan pertama melakukan reaksi antara gliserol dan asam stearat secara refluks pada range temperatur $120-160{ }^{\circ} \mathrm{C}$ selama 8 jam dengan menggunakan katalis $\mathrm{HCl}$ $5 \%$, diperoleh hasil berupa endapan putih kekuningan dengan berat 7,83 g. Percobaan kedua, diperoleh endapan putih kekuningan dengan berat 7,75 g. Percobaan ketiga hasil sintesis diperoleh endapan putih kekuningan dengan berat $8,55 \mathrm{~g}$. Rerata berat hasil sintesis adalah $8,2 \mathrm{~g}$ dengan rendemen $80,53 \%$. Hasil refluks tersebut kemudian dimurnikan dengan rekristalisasi. Senyawa yang terbentuk setelah direkristalisasi berupa padatan berwarna putih serta mempunyai titik leleh $58-59{ }^{\circ} \mathrm{C}$.

\section{Hasil Identifikasi dengan Spektrometer IR}

Dari spektrum IR senyawa hasil sintesis esterifikasi (Gambar 1), terdapat pita melebar pada 3425,58 $\mathrm{cm}^{-1}$ yang menunjukkan adanya gugus $\mathrm{OH}$ (hidroksil). Pita kuat pada $1735,93 \mathrm{~cm}^{-1}$ menunjukkan adanya gugus $\mathrm{C}=\mathrm{O}$ karbonil. Pita sedang pada $2916,37 \mathrm{~cm}^{-1}$ menunjukkan adanya gugus $\mathrm{CH}$ alifatik. Pita kuat pada $1180,44 \mathrm{~cm}^{-1}$ menunjukkan adanya CO gugus ester. Dari spektrum IR tersebut dapat disimpulkan bahwa dalam senyawa yang dianalisis terdapat gugus $\mathrm{OH}$ hidroksil, $\mathrm{CH}$ alifatik, $\mathrm{C}=\mathrm{O}$ karbonil dan $\mathrm{CO}$ ester.

\section{Hasil Analisis secara Spektrometer GC-MS}

Data spektroskopi GC-MS senyawa hasil sintesis terdapat pada Gambar 2. Senyawa hasil sintesis memiliki 2 puncak. Puncak tertinggi memiliki kelimpahan 98,94\%. dan m/e 358, puncak 1 memiliki kelimpahan $1,06 \%$ dan $\mathrm{m} / \mathrm{e} 298$.

Puncak 1 dengan kelimpahan 1,06\% dan m/e 298 memiliki kemiripan dengan senyawa asam stearat. Hal ini didukung oleh SI sebesar 95 yang mirip dengan senyawa asam stearat serta fragmentasi dan $\mathrm{m} / \mathrm{e}$ pada spektra massa yang muncul mirip dengan fragmentasi dan m/e spektra massa senyawa asam stearat. Asam stearat merupakan bahan dasar dalam reaksi ini, sehingga sangat dimungkinkan masih terdapat sisa.

Puncak 2 dengan kelimpahan 98,94\% dan m/e 358 memiliki kemiripan dengan senyawa gliserol 2-monostearat dengan 


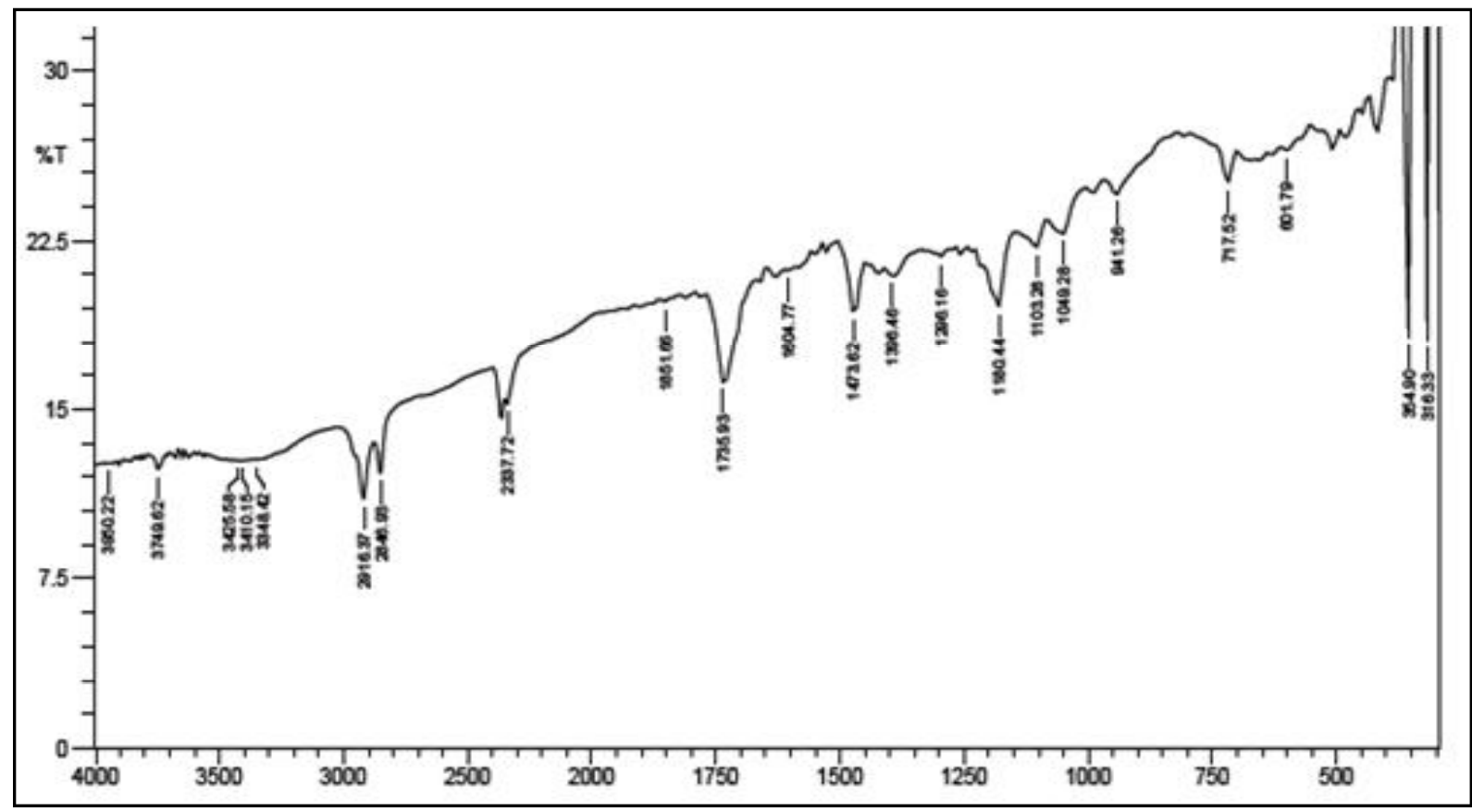

Gambar 1. Spektrum IR Senyawa Hasil Sintesis

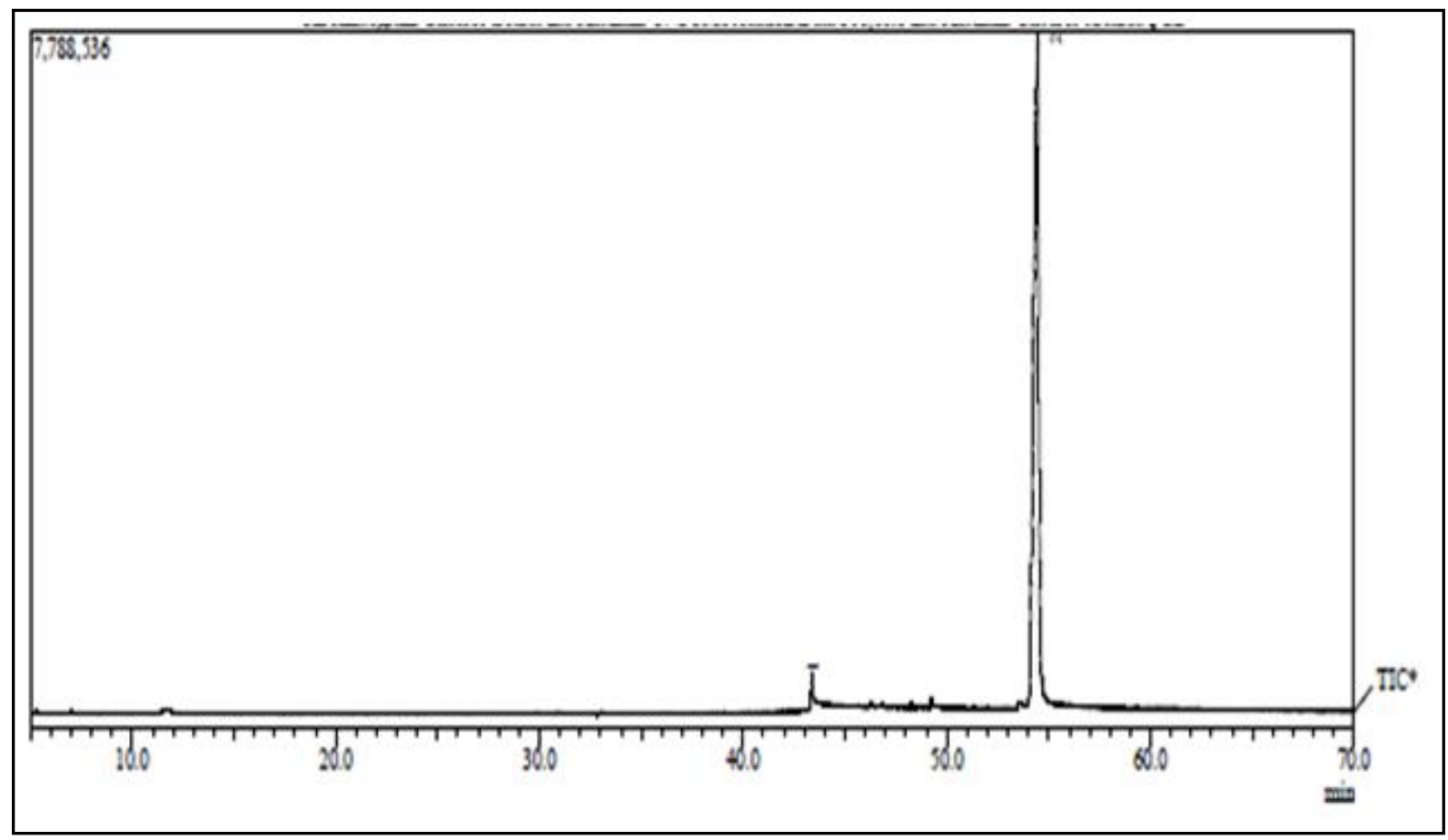

Gambar 2. Spektrum GC-MS Senyawa Hasil Sintesis

index similarity (SI) sebesar 88\% Dengan demikian senyawa hasil sintesis adalah gliserol 2-monostearat. Data spektrum MS senyawa hasil sintesis adalah $358(\mathrm{M}+), 327$, 267, dan 43, sehingga dapat digambarkan pola fregmentasinya seperti Gambar 3. 


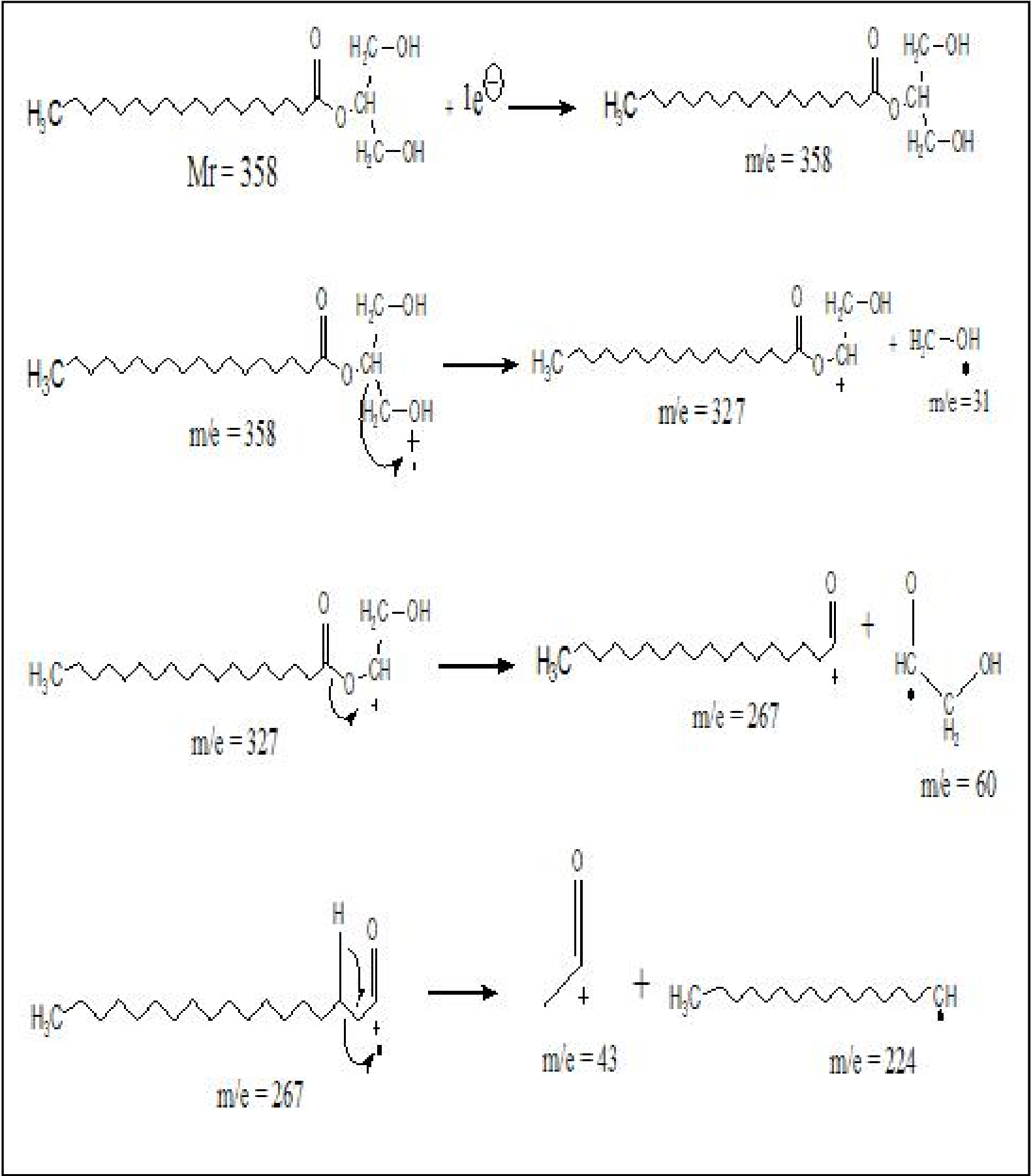

Gambar 3. Pola Fragmentasi Senyawa Hasil Sintesis

\section{KESIMPULAN}

Hasil penelitian menunjukkan bahwa gliserol stearat dapat dibuat dari asam stearat dengan gliserol hasil samping pembuatan biodiesel dari minyak jelantah melalui reaksi esterifikasi menggunakan katalis $\mathrm{HCl}$ pekat dan secara refluks pada temperatur 120-160 ${ }^{\circ} \mathrm{C}$ selama 8 jam. Senyawa hasil sintesis berupa padatan berwarna putih kekuningan, memiliki titik leleh 58-59 ${ }^{\circ} \mathrm{C}$. Senyawa 
Jurnal Penelitian Saintek, Vol. 20, Nomor 1, April 2015

hasil sintesis memiliki massa molekul yaitu 358 memiliki kemiripan dengan gliserol-2monostearat dengan SI sebesar 88\% dan kemurnian $98,94 \%$.

\section{DAFTAR PUSTAKA}

Darnoko, D., and Cheryan, M. 2000a. Kinetics of Palm Oil Transesterification in a Batch Reactor. JAOCS. Vol. 77, No 1.

Darnoko, D., and Cheryan, M. 2000b.Continuous Production of Palm Metyl Ester. J. Am.Oil Chem.Soc., 77, 1269-1272.

Hilyati, Wuryaningsih, Anah, L. 2001. Pembuatan Gliserol Monostearat dari
Gliserol dan Asam Stearat Minyak Sawit. Prosiding Seminar Nasional X "Kimia dalam Industri dan Lingkungan".

Ketaren, S. 1986. Pengantar Teknologi Minyak dan Lemak Pangan. Jakarta:UIPress.

Pagliaro, M., and Rossi, M. 2008. The Future of Glycerol: New Uses of a Versatile Raw Material; RSC Green Chemistry Book Series. Chambridge: Royal Society of Chemistry.

Widayat. 2012. Potensi Gliserol dalam Pembuatan Turunan Gliserol Melalui Proses Esterifikasi. Jurnal Ilmu Lingkungan, Vol. 10. 26-31. 